Portland State University

PDXScholar

\title{
Technology-Based Training for Older Employees: A Literature Review
}

Daria Maletis

Portland State University

Follow this and additional works at: https://pdxscholar.library.pdx.edu/honorstheses Let us know how access to this document benefits you.

Recommended Citation

Maletis, Daria, "Technology-Based Training for Older Employees: A Literature Review" (2014). University Honors Theses. Paper 110.

https://doi.org/10.15760/honors.110

This Thesis is brought to you for free and open access. It has been accepted for inclusion in University Honors Theses by an authorized administrator of PDXScholar. Please contact us if we can make this document more accessible: pdxscholar@pdx.edu. 
Technology-Based Training for Older Employees: A Literature review

by

Daria Maletis

An undergraduate honors thesis submitted in partial fulfillment of the

requirements for the degree of

Bachelor of Arts

in

University Honors

and

Psychology

Thesis Adviser

Dr. Donald Truxillo

Portland State University 
Abstract

Technology-based training is being increasingly adopted by organizations of all sizes. It allows employers to cut costs and to train more employees at the same time. However, arguably the greatest benefit of computer-based training is that it is very flexible and can be customized to the needs of the organization as well as to the individual needs of the trainees. This paper explores what adjustments can be made to computerized training programs for older employees to make their learning most effective. The results of the literature review show that older adults benefit from simple and consistent interface design, large font and empty video background, instructional coherence and redundancy, error management approaches, and goal-setting strategies. Specific goals are better than general goals, and learning goals are more effective than performance goals. Conceptual mapping was found to be a very effective metacognitive strategy. Previous experience with technology was an important factor in predicting older trainees' cognitive workload and frustration levels. Some of these factors, especially those oriented towards reducing cognitive load may be equally helpful for younger trainees; however, some like redundancy may be detrimental to younger trainees' learning. More research is needed to determine the interaction between individual variables and different training strategies.

Keywords: training, computers, e-learning, web-based training, technology-based training, older employees, aging workforce, cognitive aging. 


\section{Introduction}

The American workforce is surely growing older. In 2013, $44 \%$ of all workers in the U.S. were 45 years old and above. In 1992, this number was only $29 \%$. The cohort of $65+$ is the fastest growing — as many as 7.6 million people of this age are currently employed in the U.S., and this number is expected to almost double by 2022 (Bureau of Labor Statistics 2012, 2013).

Industrial change is happening at a faster rate, too. Frey and Osborne (2013) estimate that roughly $47 \%$ of all American jobs will become automated in a decade or two, with some jobs being at higher risk for computerization than the others. These changes in the labor market will necessitate more employee training and retraining, and older workers will represent a large part of the trainee cohort.

The present project reviews existing literature in the field of technology-based training for older adults to produce evidence for what constitutes the most effective training program for them. Specifically, I will examine what changes in cognitive processes and in motivation occur as a person ages in the introduction section. Next, I will describe the methods for conducting literature search for this project in the methods section. Then I will review the findings of the literature search that will be cover such aspects of training design as technology interface, goalsetting, error management, metacognitive strategies, and trainee computer attitudes. A table with the summary of studies' results will be provided as well. In the same section, I will discuss the relationship between different findings and their implications for our understanding of cognitive aging, training, and direction of the future research.

\section{Age and Learning Technology}

Technology-based training is being increasingly adopted by organizations of all sizes (Docebo, 2014). It allows employers to cut costs and to train more employees at the same time. 
However, arguably the greatest benefit of computer-based training is that it is very flexible and can be customized to the needs of the organization as well as to the individual needs of the trainees. Understanding how different individuals and groups interact with learning technology is crucial in designing the most effective training programs for them. Older employees faced with challenges of aging may have special needs that need be addressed by training design.

There is no agreement among scholars on what constitutes an 'older employee'. In the U.S., the Age Discrimination in Employment Act of 1967 designates a person 40 years of age and above as an older employee. However, this age is simply a legal heuristic in the U.S. as to when discrimination might start to take place (or at least when it did in the 1960s) and is not based in the science behind what is an "older worker" or when age is likely to affect a person's ability to do their job or to learn new skills. Further, as the labor force participation rate among older individuals rises, the of 40-50 year-olds cohort should be more accurately described as middle aged employees, not older employees. In the industrial/organizational psychology literature, the cut off for "older employees" varies from study to study and can be anywhere from 40 to 65 years (Van Rooij, 2012; Kelley \&Charness, 1995).

The matters get even more complicated when we try to compare different fields of psychology. Special treatment of older adults in the workplace is based on the premise that their cognitive and sensory-motor abilities are significantly diminished compared to those of their younger colleagues. However, studies in cognitive psychology which report age-related cognitive deficits have a much higher cut off for the 'older adults' group: it usually starts with 65 years and the mean age is around 71 (Seeman, 2001; Colcombe \& Kramer, 2003; Van Hooren, 2007). Because this age is beyond standard retirement, this makes the findings from cognitive psychology about older adults' cognitive and sensory-motor functioning only partially applicable 
to the older workforce. Thus, it is necessary to look at the empirical data related to the age cohort in question (40-65 y.o.) to determine how their cognitive, sensory-motor and sociocultural functioning impact their work performance and ability to learn. And even then, age-related decline does not need to be treated as intellectual disability, as there is evidence that the proper environment and proper training allow older adults to learn - almost as quickly and well as younger adults.

\section{Aging and Cognitive Changes}

Van Rooij (2012) presents an interesting take on age-related cognitive deficits. This perspective states that learning ability does not decline with age. Rather, older adults' inferior performance may be due to the impact of negative age-related stereotypes and the ways we measure learning (Hultsch, 1977; Howard \& Wiggs, 1993). In some ways, this may be accurate as negative age-related stereotypes are indeed quite prevalent and have a detrimental effect on one's self-efficacy and, as a result, performance (Kanfer \& Ackerman, 2004; Ng \& Feldman, 2012).

However, age-related cognitive decline has also been observed and well documented by cognitive and developmental psychologists. Age-related deficits are apparent by the age of 65 and can become more dramatic in a person's early 70s (Kim et al. 2007; Wolfson, Cavanagh, \& Kraiger; 2014) and the correlation between age and cognitive speed tasks was found to be -.47 (Salthouse, 2003; Wolfson, Cavanagh \& Kraiger, 2014). There is also biological evidence for age-related cognitive decline in older adults. Although neuroplasticity was found to be present even in adults, the brain's functioning becomes compromised over time due to natural brain volume decline and due to accumulation of brain lesions. Both these factors greatly impact 
seniors' cognitive ability and functioning (Buckner, Head \& Lustig, 2006). Again, however, much of these research concerns geriatric samples which are beyond the standard retirement age.

Another important aspect of cognitive aging is general slowing in the rate of information processing (Birren, 1974; Salthouse, 1996). Charness (2009) reports that on average older adults will take between 50 and 100 percent more time than younger adults on most tasks. Older adults also reportedly have difficulty self-initiating metacognitive activities even when they are fully capable of utilizing it (Tourin \& Hertzog, 2004).

On the other hand, research has demonstrated that some human cognitive abilities assume different developmental trajectories. For example, two major clusters of cognitive abilities crystallized intelligence and fluid intelligence — are impacted by age in different ways and to various degrees. Fluid intelligence relates to cognitive operations that are implicated in problemsolving. They include working memory, attention, abstract reasoning, coordination and integration of information, task switching, and inhibition (Kanfer \& Ackerman, 2004; Wolfson, Cavanagh, \& Kraiger, 2013). Fluid intelligence peaks in the early 20s, and then slowly declines throughout adulthood. Older adults experience monitoring deficits in their memory judgments and in their actions (Daniels, Toth, \& Jacoby; 2006). Working memory, a system for storing and manipulating information, is subject to age-related decline (Charness, 2009; Wolfson, Cavanagh, \& Kraiger, 2013). Older adults experience a slight decline in short-term memory as well, but it is not as significant as the working-memory decline. Poffenberger (1942) suggested that the decline occurs at the rate of $1-1.5 \%$ per year from the age of 25 and to the age of 50-55; after that fluid abilities diminish more dramatically (p.65).

Crystallized intelligence refers to sociocultural and specialized knowledge like facts, names, concepts and links between them, vocabulary, and verbal comprehension (Kanfer \& 
Ackerman, 2004). Anything that is the end product of information processing belongs in the domain of crystallized intelligence. This ability increases with age, peaks in the 50s or 60s and declines slightly afterwards (Charness, 2009; p.238). Researchers point out that crystallized intelligence presents a very wide domain of knowledge and cannot be always effectively assessed via intelligence tests. A way to measure crystallized intelligence would be through knowledge tests which include both occupational and general knowledge.

Crystallized intelligence is thought to compensate for fluid intelligence to some degree in the performance of most jobs. For example, with some notable exceptions, CEOs and top managers are mostly older persons; in other words, decrements in fluid intelligence do not seem to hinder people in the performance of these jobs. On the other hand, only a few jobs require fluid intelligence, and age can impact the successful performance of these jobs. For example, most countries have age limits for the job of air traffic controller, and trainees for these jobs required to be under the age of 35 .

\section{Age and Computer-Based Training}

In regards to computer training, Kelley and Charness (1995) report that older adults on average spend more time on computer tasks, make more errors, and require more assistance from the trainer (p.108). They suggest that the decline in spatial ability could be the factor that most strongly influences older adults' learning in computerized environment. Spatial ability is implicated in operating the mouse, locating the cursor and the text on the screen, and remembering the source of previously viewed information. Older adults were found to struggle significantly more with all of these activities compared to younger adults. Working memory decline, problem-solving ability, attentional deficit, and prior experience also affect older 
trainees' computer performance. Older adults experience more computer-related anxiety, too, which is associated in part with their initial inferior performance in computerized environment.

Although the process and the effects of aging cannot be reversed, appropriate environment and training strategies can enhance older adults' learning and performance. Two major theories that relate to human learning in computerized environment are Cognitive Load Theory (CLT) and Cognitive Theory of Multimedia Learning (CTML). Although not aging theories specifically, CLT and CTML provide insight into how limited cognitive capacity (which older adults supposedly experience) shapes learning. It is commonly believed that older adults have fewer cognitive resources compared to younger adults, and thus CLT and CTML have important practical implications for designing training programs for them (Wolfson, Cavanagh \& Kraiger, 2014).

The main premise of CLT is that working memory has a limited capacity and that training instruction should avoid overloading it. Cognitive overload results in inability of the learner to effectively process and store information and thus inhibits learning. Intrinsic and extraneous factors can both be the source of load on working memory. Intrinsic factors include amount of learning material, as well as its relevance and difficulty. (Sweller et al. 1998; Van Merrienboer \& Sweller, 2005; Wolfson, Cavanagh \& Kraiger, 2014). Extraneous factors include activities that are not directly related to instructional material and which cause distraction and cognitive overload. Unsuitable instructional design and superfluous information may be the source of extraneous cognitive load (Ginns, 2006).

CTML considers how working memory operates in the multimedia environment where the learner has to simultaneously process information from multiple sources (e.g., reading text, viewing animations, and listening to the lecturer) (Wolfson, Cavanagh \& Kraiger, 2014). The 
main concern of CTML is not the amount of cognitive resources like in CLT but attention and its limits (Mayer, 2005). CTML is based on the assumption that learning occurs in three steps: (a) attending to relevant information, (b) mentally organizing the information into conceptual model and (c) integrating the mental model into the framework of existing knowledge. (Mayer, 2005; Kraiger, 2014).

\section{Age and Work Motivation}

At the same time, there appear to be differences in the motivation of older and younger workers, and these can affect training and learning as well. Kooij et al. (2011) found that age was negatively associated with growth and security motives and positively associated with intrinsic motives for work and social work-related motives. Older adults are reportedly less interested in career advancement and professional training and are more motivated by the social benefits that the work provides like good relationship with others, interpersonal communication, and an opportunity to share their personal experience with younger employees. These findings of differential motives for younger workers (e.g., advancement) versus older workers (e.g., social relationships and applying accumulated skills) are consistent with the tenets of Socioemtonal Selectivity Theory (SST; Carstensen et al., 1999), a major lifespan development theory. However, the negative relationship between age and growth motives was observed only in traditional white- collar workers; in blue-collar workers, it was positive and in managers such a relationship was absent. Blue collar workers also exhibited higher intrinsic motivation for work than white-collar workers. This suggests that further research on work motivation should discriminate between different professions, job fields, and organizational ranks.

Kanfer and Ackerman (2004) may have an explanation for this age-related difference in work motives. They suggest that older adults are well aware of the decline in their fluid 
intelligence and executive functions and so they tend to choose tasks in which they can rely less on their fluid abilities and capitalize on crystallized abilities (p.444). This is consistent with another lifespan development theory, Selection, Optimization, and Compensation (SOC) theory (Baltes \& Baltes, 1990). They argue that protecting self-concept becomes a priority in older adults. Therefore, older adults will engage in activities that reinforce their self-concept and avoid activities that threaten it. Training initially places a high demand on fluid intelligence and decreases the effort-performance function which may induce anxiety and frustration in older employees. The authors suggest that achievement and career growth motives decline with age and become replaced by motives that are related to protecting self-concept and promoting positive affect.

Finally, there has also been some work that considers older workers general interest and motivation towards training. In a meta-analytic study, Ng and Feldman (2012) examined a number of common older worker stereotypes to see if they actually were true. For example, they examined whether older workers really do have lower work performance and found that this was not the case. Interesting to the present discussion, however, they did find that one stereotype, lower interest in work-related training, may be true. This is consistent with the research and theory discussed above (Baltes \& Baltes, 1990; Carstensen et al., 1999; Kanfer \& Ackerman, 2004; Kooij et al., 2011) because training may not be instrumental to older workers' goals of developing social relationships, sharing knowledge, and applying current skills.

\section{Summary}

This literature review above suggests a number of differences that have been observed in older and younger workers' training performance, especially that delivered via computer technology. This review suggests that differences may be due to cognitive and motivation 
TRAINING FOR OLDER EMPLOYEES: A LITERATURE REVIEW

changes. In the following section, I focus on literature specifically addressing older adults learning via computerized and online media.

\section{Method}

I conducted a literature search through PsycINFO and WebMD databases. I used different combinations of the words - training, computer, technology, older, and elder -to find empirical studies from peer-reviewed journals that were published in English between 1994 and 2014. I chose this particular range because of the technological changes that have occurred over the last 20 years. For PsychINFO, I applied an additional age group criterion, specifically, I searched for studies participants in which were middle aged (40-64 y.o.) and aged (65-85 y.o.). I included the following search terms: aging, training, computer assisted instruction, computer training, computer games, cognitive ability, cognitive impairment, computer applications, computers, gerontology, human computer interaction, technology, computer software, memory training, brain, computer literacy, personnel training, information technology, internet, memory, short-term memory, assistive technology, attention, intervention, treatment effectiveness evaluation, adult attitudes, cognition, cognitive control, computer attitudes, geriatrics, internet usage, learning, motivation, neural plasticity, neuropsychological assessment, oral communication, performance, robotics, transfer (learning), virtual reality, adult learning, business and industrial personnel, cognitive processes, cognitive processing speed, cognitive techniques, decision support system, educational programs, employee attitudes, executive function, human females, human sex differences, motor coordination, motor processes, selective attention, self-efficacy, self-esteem, skill learning, social support, teaching methods, visual discrimination, visual displays, word processes, work teams, motor skills, multimedia, peers. 
The search yielded 124 articles. I selected 42 articles for the review based on their abstracts' relevance to the topic of study. I included 19 papers in the final review after reading the full text of each article and determining whether it met the selection criteria. To be included in the review, the study had to specify older adults (40 y.o. and above) as its participant group and provide corresponding age analysis in the results section. It also had to focus on training and strategies aimed at improving training outcomes (e.g., learning and transfer). Finally, training had to be delivered via technological devices which includes computer based training, web-based training, e-learning, video-game training, and virtual simulation training.

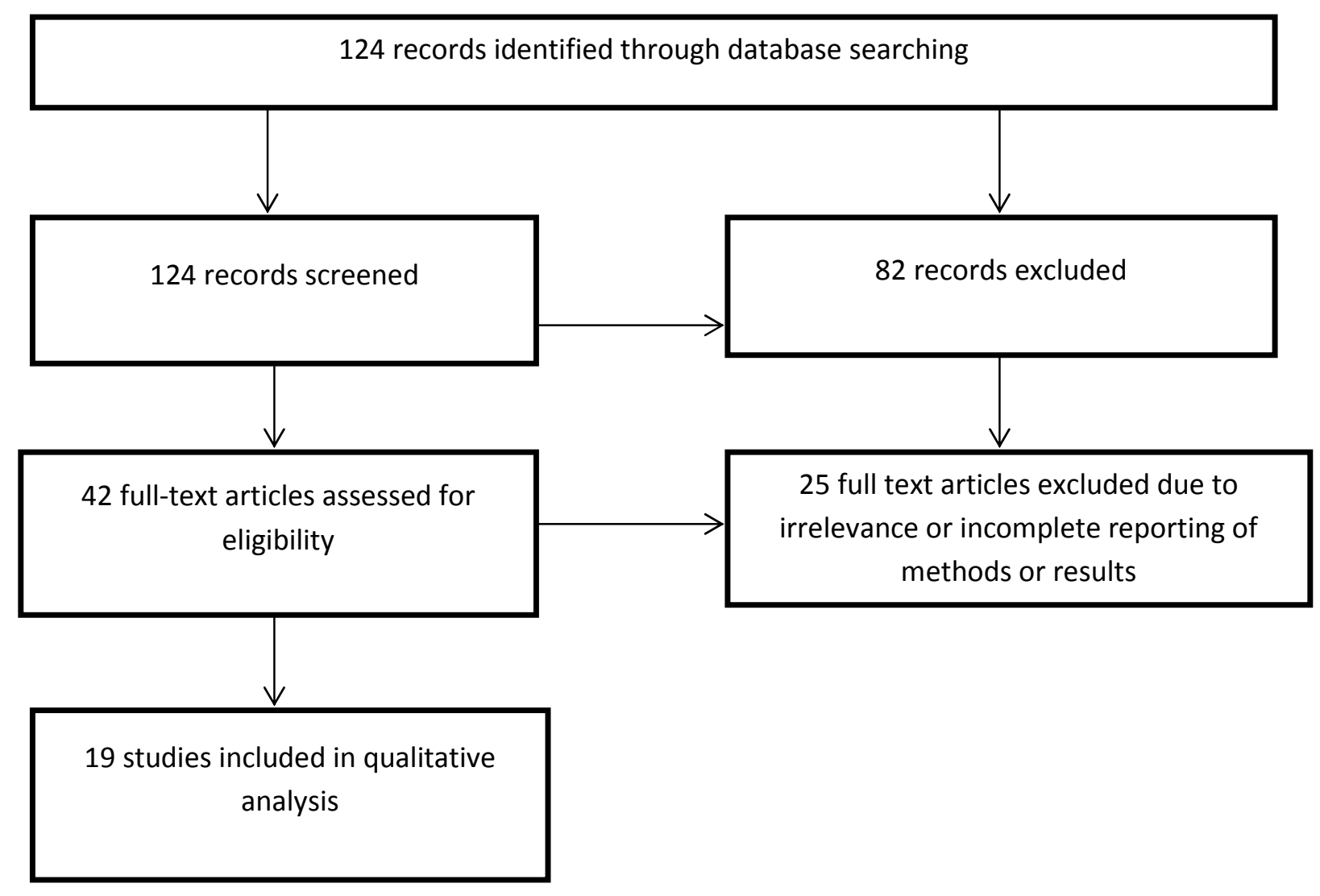

Figure1. A flow chart of studies selection

\section{Results}


TRAINING FOR OLDER EMPLOYEES: A LITERATURE REVIEW

In this section, I review the relevant studies and narrative reviews on age and learning. Then, based on this review, I offer research propositions for future research on age and computerized/online training design.

\section{Computer Interface Effects}

Menu and icon effects. The fact that older adults experience a decline in working memory has led researchers (Kelley \& Charness, 1995) to believe that an interface that utilizes menus and icons will be more beneficial to them than keystrokes as it is more challenging to memorize key combinations than to pick a command from those available on the screen. However Charness (2001) found that the benefits of the visual display which utilizes menus and icons were not age specific. Seventy-two computer novices ages 19 to 88 participated in word processing training. The three experimental conditions included keystroke interface, menus interface, and menus plus icons interface. In the first condition, commands could only be accessed via keystrokes; the second condition allowed participants to use fold-out menus with the keystrokes disabled; the third condition was identical to the second and also included formatting icon bars. Menus and menus-plus-icons conditions required trainees to use a mouse for command input. Dependent variables were post-test performance, time spent completing the test, and the number of errors. There was no interaction between age and interface was found. In fact, performance was better in the menus and menus-plus-icons conditions for both younger and older adults. Menus and menus-plus-icons interface yielded a 35\% increase in final test performance accuracy and a $48 \%$ increase in error-free performance. In other words, design issues that were thought to be especially helpful to older workers in the end benefitted both older and younger workers. Interestingly, results also showed that education and gender were 
significant predictors of overall performance: higher educated individuals performed better and women completed the test faster and more accurately than men.

Redundancy. Pachman and Ke (2012) studied the impact of redundancy on learning. In organizational psychology, redundancy is a delivery of the duplicate information via different channels (e.g., trainees read the text and listen to it being narrated by the trainer). The authors hypothesized that redundancy would lower trainees' performance as it would not add any new details about the subject and would increase participants' cognitive. Twenty-three younger $(\mathrm{r}=18-35 ; \mathrm{M}$ age $=24.65$ years $)$ and 20 older adults $(\mathrm{r}=60-84 ; \mathrm{M}$ age $=73$ years $)$ participants were randomly assigned to either redundant or non-redundant condition. In the redundant condition, written text was presented on the screen in addition to audio and visual information. In the nonredundant condition, the text was absent. The researchers measured trainees' knowledge retention, transfer, mental effort, and learning and performance efficiency.

Results revealed that redundancy was detrimental for younger trainees' learning: their performance was significantly worse than in the non-redundant condition. At the same time, older trainees benefited from redundancy: their learning and transfer were significantly better when information was presented via several channels. Thus, the results of this study provide an interesting contrast the training design needs of older and younger workers. At the same time, it is important to note that the older group in this study was largely beyond the traditional retirement age in most countries, such that is may be less applicable to many organizational settings. Research is needed to see if similar redundancy effects are found in older groups in their 50s and 60s; such a study is described next.

Another study on redundancy was done by Wallen and Mulloy (2006). They tested a computer-based safety training program on a group of 50 factory workers divided into cohorts of 
26-43 year-olds and 44-64 year-olds. The program interface included either text, text with pictures, or text with pictures and audio narration. A multiple-choice test and a problem-solving test were given to the participants immediately after the training to measure their learning outcomes. Experimenters found no impact of age on performance on the multiple choice test; however, younger trainees did better than older trainees on the transfer test. Text and pictures were significantly better for younger adults than for older adults. Text, pictures and narration were much better for older adults. Older adults also performed much worse when interface included only text. The authors concluded that narration, as well as redundancy (text, pictures, and animation) lessens the load on older learners working memory and frees cognitive resources for processing of task-relevant information. Taken together, these two studies suggest that redundancy may help older trainees to learn more effectively.

Adaptive interface effects. Bruder, Blessing, and Wandke (2013) studied the effect of an adaptive interface and adaptive advice on older trainees' performance. 48 adults between 54 and 77 years of age $(\mathrm{M}$ age=66 years) were instructed in how to operate a cell phone. Researchers used two types of cell phone interface-complete interface and adaptive interface. A complete interface included all cell phone functions, while adaptive interface started with basic functions and subsequently increased in complexity gradually revealing new functions to the users. Adaptive advice was delivered in the form computer feedback on learner's performance. Whenever the lesson was not learned appropriately, the program suggested the trainee go back and review previous exercises. Training effort (i.e., perceived effort during and after the training), training success (i.e., test performance and content knowledge), trainees' self-efficacy and satisfaction with training were measured as dependent variables. 
The adaptive interface group was more efficient in their learning and requested less support from the trainer both during the post-training test and the transfer test. Trainees in this condition had a better mental representation of the cell phone's structure and scored higher on the knowledge test. The growing complexity interface also improved older trainees' procedural knowledge and learning efficiency. The results did not confirm the effectiveness of adaptive advice, however. Adaptive advice did not contribute to training success and only increased learners' perceived effort, perhaps because trainees viewed computer's suggestion to review a lesson as negative feedback and were more discouraged to continue training.

Miscellaneous. Rivera-Nivar, Pomales-Garcia (2010) studied how camera focus, video background and video size, gender of the instructor and the content of the influence performance of younger (22-35 y.o.) and older (55-65 y.o.) trainees. The dependent variables were information recall, task workload, disorientation, and training satisfaction. Researchers found that older trainees performed significantly better when the lesson type was narrative rather than numerical, when there was no background in the video and when the video display was large. Older trainees were more satisfied with narrative lesson type than the younger trainees and engaged in less perceived effort in this condition. Perceived effort serves as a measure of task overload, and it is important to keep it under control, especially in older adults training. Gender of the instructor was irrelevant for trainees' performance.

Conclusions from previous narrative reviews. Van Rooij (2012) used an adaptation of Best Evidence Synthesis (BES) to assess eighteen studies on age-inclusive organizational training. Her analysis showed that training in small groups and self-paced learning produced the highest results for older workers (defined as age 50 and above). Older adults learned best when the training content gradually increased in complexity and when its presentation was bimodal 
TRAINING FOR OLDER EMPLOYEES: A LITERATURE REVIEW

(audiovisual). Wolfson, Cavanagh, and Kraiger (2013) also recommend that training programs

for older employees have a simple and consistent design, are highly structured and based on the principles of the Cognitive Theory of Multimedia Learning (CTML) and the Cognitive Load Theory (CLT).

Research propositions. Based on the above empirical studies and reviews, I make the following research propositions regarding training design for an aging workforce.

Proposition 1: The training program interface for older workers should be simple and include large video display with large font size and no background.

Proposition 2: The training program interface should utilize redundancy.

Proposition 3: The training program interface should minimize irrelevant information.

Proposition 4: The interface needs to rely on menus and icons rather than the keystrokes to lessen the load on working memory.

Proposition 5: Learning schemas that start out with the basic concepts and gradually increase in complexity should be included in the training program for older adults.

\section{Goals}

Goal setting has received quite a bit attention in the training literature as well, with the general consensus that setting specific goals for trainees is beneficial to them. Hollis-Sawyer and Sterns (1999) investigated the impact of a goal-oriented approach on training and transfer, computer self-efficacy, computer anxiety and computer attitudes in a sample of older adults $(\mathrm{R}=50-89$ years; $\mathrm{M}$ age $=64.1$ years $)$. They suggested that goal-setting is a motivational technique that improves planning and organizing in problem-solving tasks. Goal-setting is also thought to enhance metacognitive activity in older adults as it allows the learners to identify deficiencies in their performance and to work on them. 
In this experiment, researchers compared a goal-setting approach plus verbal persuasion to simple verbal persuasion in terms of their impact on older trainees' performance and selfefficacy. Verbal persuasion consisted of the trainer providing feedback to the trainee on his/her performance and discussing trainee's changes in the perception of task difficulty and the ways to improve performance. The trainer provided only positive feedback and remained available to the trainee at all times during training. Regarding the success strategy, participants in the verbal persuasion condition were told to do their best. The goal-oriented approach, on the other hand, added goal-setting to verbal persuasion. In this condition, the goal for the first trial was assigned to the trainee by the experimenter and all subsequent goals were set by trainer and trainee together. The goals were required to be specific and moderately challenging. Trainees' performance, self-efficacy, computer anxiety and general attitude towards training were measured as dependent variables.

Both training conditions resulted in improved trainee performance, but trainees in the goal-oriented condition showed a significantly steeper rate of improvement during the first half of training processes. The two groups were not significantly different in regards to task completion time. However, trainees in the goal-setting condition completed the near-transfer task significantly faster and more accurately. The authors also report that trainees in the goal-oriented condition had higher-self-efficacy during and after the training, more positive post-training attitudes towards computers, and lower computer anxiety.

Zumbach and Reimann (2001) compared strategy training to a goal-setting approach. Sixty participants between ages 17 and 53 received a task which consisted of developing arguments about am oil spill's effects on the ecosystem after reading the hypertext and following different links. Participants in the goal-based (GBS) condition developed their goals together 
with the trainer. They worked in the role of a newspaper editor and were told that they needed to write an editorial piece on an oil tanker accident. Participants in the strategy condition received training in asking critical questions prior to starting on the task. This was done through presenting them with examples where links between facts and concepts were analyzed and evaluated. A control condition consisted of participants simply following the instructions in the tutorial to develop arguments about the oil spill. Researchers measured trainees' conceptual knowledge, factual knowledge, motivation, and qualitative and quantitative aspects of their arguments.

Trainees in the GBS condition performed significantly better on the posttest than the trainees in two other conditions. They had a much more elaborate concept map and displayed a higher level of structural knowledge. GBS group also produced more sound arguments than the other two groups. These trainees were also more motivated to complete the task and to engage in the similar activity in the future. Strategy training was not particularly effective and did not differ much from the tutorial instruction. The authors conclude that trainees need more direct guidance when they are confronted with new learning material. Such guidance may include clearly stating the expectations of the course, helping them develop their own goals and providing them with tools to create appropriate conceptual maps.

Paas, Camp, and Rikers (2001), on the other hand, hypothesized that specific goals impose too much load working memory and may result in cognitive overload in older adults. They suggested that goal-oriented problems prompt trainees to engage in means-end analysis and divert their limited cognitive resources away from exploration. As older adults have fewer available cognitive resources, the benefits of goal-free learning should be especially pronounced for them. 
For their experiment, the researchers randomly assigned young $(\mathrm{M}$ age $=20.2$ years $)$ and old (M age=72.4) participants to a goal-specific or goal-free condition on a computerized mazetracing task. The maze-tracing task required participants to find the designated area in the maze that was either visible (goal-specific) or invisible (goal-free) to them. Upon completion of the training task, participants were asked to locate the same goal in the identical maze pattern (measure of learning) and to locate the goal going backwards from finish to start (measure of transfer). Both younger and older adults completed the task faster in the goal-free condition. Younger participants did better than older participants in both conditions, but both young and old adults completed the training task in the goal-free condition. There was found to be a significant Age x Goal Specificity interaction, suggesting that goal-specificity was more detrimental for older adults' performance than younger adults' performance. The test maze results revealed that the goal-free condition was more beneficial for learning and transfer for both age groups. Age differences were again more significant in the goal-specific condition than in the goal-free condition and Age x Goal Specificity interaction was significant too. These results suggest that older workers may benefit from training design that allows for more exploration and experimentation and does not focus as much on specific goals. However, given that these results are counter to much of the majority work on goal setting over the past 40 years, especially in training, they should be interpreted with caution. For example, they may be due to certain specific sample or task characteristics.

Proposition 6: Goal-setting in training is superior to a general strategy training approach. Goals help learners to direct their cognitive resources to the task at hand, stay more motivated throughout training, and increase their self-efficacy. Trainees with clearly defined 
TRAINING FOR OLDER EMPLOYEES: A LITERATURE REVIEW

goals exhibit higher rates of structural knowledge and learn significantly faster than trainees

who do not have specific goals.

\section{Error management}

Kelley and Charness (1995) suggested that as older adults experience more computerrelated anxiety, they should be trained to incorporate errors into their learning. Specifically, trainers need to teach them how to minimize the negative consequences of errors, brief the trainees on the beneficial nature of making mistakes, and encourage them to make mistakes rather than avoid them. An approach in which trainees are encouraged to focus on the benefits of errors is called error management training or EMT. EMT is supposed to boost learning by allowing trainees to engage in active exploration and experimentation.

Carter and Beier (2010) suggested that error management as a type of supportive environment would benefit older workers more than younger workers. They also hypothesized that the extent of their improvement would depend on individual differences and the training structure. One-hundred seventy-three participants between 20 and 66 years old were asked to complete training on Microsoft Access computer application. Three experimental conditions included low structure plus EMT; high structure plus EMT and high structure and no instructions. High-structure condition differed from low-structure condition in the way that trainers provided trainees with detailed, step-by-step instructions on how to complete each task. EMT consisted of reminders about beneficial nature of mistakes that were delivered via headphones and appeared on the screen throughout training.

The only statistically significant age-related finding was that the higher older adults were in cognitive ability, the more they benefitted from EMT. The authors suggest that EMT helped older adults to focus their limited cognitive resources on the task and the more of those cognitive 
resources they had, the better their performance was. Another plausible explanation of EMT's effectiveness in the older adults' group is that they were more concerned about making errors than younger adults even when the task did not provide much room for errors. In this way, EMT could have operated as a self-regulatory strategy.

Younger adults benefitted EMT only if they were low in cognitive ability. This may be explained by the fact that younger adult high in cognitive ability have ample cognitive resources to complete the task and do not require adaptive instructions. There was no three-way interaction of age, ability, and structure on training outcomes. The only disadvantage of low structure plus EMT was that it took trainees longer to complete the task compared to the high structure conditions. Low-structure training, therefore, may be not very efficient when time is a particular concern.

Chillarege, Nordstrom, and Willimas (2003) assessed the effectiveness of error management training when it was coupled with different goal types. In this experiment, 67 older workers (ages 40+) signed up for two free Word processing training sessions. They were assigned to one of the four conditions: EMT+ learning goal, EMT+ performance goal, error avoidance+ learning goal, error avoidance+ performance goal. In error avoidance condition, trainees were told that errors inhibit learning and should be avoided. Learning goal instructions stressed that the trainee's goal was individual improvement and computer mastery (p.375). Performance goal instructions stated that trainee's goal was to demonstrate a high level of performance relative to others. It was also mentioned that training success was indicative of cognitive ability (p.376).

Results showed that participants in the EMT condition successfully completed more assignments on the post-training test. Learning goals also had an effect on performance with 
participants in this condition completing more assignments than the participants in performance goal condition. EMT also resulted in higher scores on the learning quiz. The goal type did not have a significant effect on learning quiz scores. Contrary to what was expected, the researchers did not find any effect of either error strategy or goal type on participants' frustration levels. Participants in the learning goal condition reported higher rates of intrinsic motivation than those in the performance goal condition. The error strategy did not have a significant effect on trainees' motivation. EMT participants requested more help from trainers than error avoidance participants. Goal type did not affect the amount of help requested by trainees.

An environment that encourages mistakes rather than penalizes them seems to produce higher training outcomes as well (Van Rooij, 2012).

Proposition 7: Error management benefits all learners but is especially helpful for older adults. Reminding older trainees that errors are an integral part of learning helps reduce their anxiety, improves motivation for learning, and results in higher post-training performance. EMT was shown to be effective when combined with low training structure and with learning goals. However, individual differences such as cognitive ability may moderate this effect.

Proposition 8: Trainers should encourage trainees to set learning goals rather than performance goals. Learning goals help trainees focus on personal growth and development and increase their intrinsic motivation for training.

\section{Metacognitive Strategies}

Providing trainees with a conceptual map was shown to be a very effective strategy for learning. It is important for the conceptual map to be specific and to target concrete concepts applicable to trainees' future jobs (Davis \& Yi, 2004; Hagmann, Mayer, \& Nenniger, 1997). 
Wolfson and Kraiger (2014) studied the effects of cognitive coherence and advance organizers (OA) on older adults' learning. Cognitive coherence refers to the notion that individuals learn better when the instructional material (text, lecture, or video) is limited to the relevant information. Irrelevant details increase cognitive load on learners' working memory and limits their ability to effectively process and encode material. This cognitive overload is even more apparent in older trainees. Advance organizers (AO) are frameworks and conceptual maps that are presented to the students before the training and explain the structural links between concepts and training modules. The experimenters manipulated the two independent variables (instructional coherence and $\mathrm{AO}$ ) to create a $2 \times 2$ study design with a different combination of variables. Their participants were younger $(\mathrm{M}$ age=21.7) and older adults $(\mathrm{M}$ age= 75.1). They found that the high coherence condition produced higher learning outcomes in both older and younger adults on a transfer test. Advance organizers, on the other hand, were beneficial only for older adults. The authors did not find a main effect of age on performance on information recall test. Note that the young and the old groups in thidy were at extreme ends of a continuum of working ages, so future research may want to reassess these issues with other age groups, for example, adults in their 30 s versus those in their 50 s or 60 s.

In their review of the literature on training for older people, Wolfson, Cavanagh, and Kraiger (2014) note that effective training should include feedback and adaptive guidance, and prompt trainees to engage in metacognitive activity. Strategies that improve metacognitive activity include paraphrasing information, devising and answering questions regarding the material, and using previously developed strategies to solve new problems. Older adults structure information less spontaneously and may benefit from more organization in learning. Organization of learning material can be enhanced through conceptual frameworks, advance 
organizers, and elimination of irrelevant information. Worked examples impose less load on cognitive system and free older learners' cognitive resources to be directed towards relevant information. As older adults may take more time to learn some concepts than younger adults, learning should ideally be self-paced.

Proposition 9: Advance organizers are especially helpful for older trainees. They help them organize information in meaningful ways and enhance information recall and transfer.

Proposition 10: High instructional coherence which excludes all irrelevant information significantly improves transfer in both older and younger adults.

\section{Attitudes}

Kang and Yoon (2007) found that trial-and-error behavior and frustration levels with the technology in users are significantly influenced by the amount of their background experience with electronic devices rather than by age. The researchers observed two groups of trainees 20-29 y.o. and 46-59 y.o. interact with different electronic devices, and they found that older adults made more errors and took longer to complete the task, showed more rigid exploration, and more encapsulation (repetitive searching without any useful outcome) (p.431). They also experienced more negative error consequences and made more non-effective actions. Older adults also reported higher workload and more difficulty with temporal demands. However, the researchers found that background knowledge had a main effect on the adoption of trial-and-error strategy by trainees and their cognitive workload. The latter presumably led to higher levels of frustration in trainees and was not dependent on age. For the purposes of training design, these findings suggest that background knowledge should be accounted for as an individual variable during the needs assessment stage. Older trainees with less background experience may be more prone to cognitive overload and frustration and therefore this aspect 
should be addressed in training either by eliminating the knowledge deficit or by providing them with coping strategies.

Although prior studies have reported age differences in motivation for work and motivation at work (Kanfer \& Ackerman, 2004; Kooij et al., 2011) and in the attitudes to computer-based learning, a study by Jan, Lu, and Chou (2012) did not find any significant impact of age, gender, or income on the intention to use e-learning (p.336). The authors stated that older employees just like younger employees are most susceptible to mimetic social pressure when they engage in web-training to emulate more successful, higher-status colleagues. This finding may be due to methodological issues or due to the fact that older employees focus on good social relationships in the workplace and on positive affect derived from interpersonal; communication.

Proposition 11: Cognitive overload and frustration levels in trainees depend more on background experience with technology and less on the age of the trainee. In fact, background experience may explain some age differences in training.

A summary of the articles reviewed in this results section is presented in Table 1.

Table 1. Summary of findings reported by reviewed articles on age and employee training.

\begin{tabular}{|l|l|}
\hline \multicolumn{1}{|c|}{ Author } & \multicolumn{1}{c|}{ Main Findings } \\
\hline \multicolumn{2}{|c|}{ Computer interface effects } \\
\hline Charness & Menus and menus-plus-icons interfaces are more beneficial for all \\
trainees regardless of age than the keystrokes.
\end{tabular}


TRAINING FOR OLDER EMPLOYEES: A LITERATURE REVIEW

\begin{tabular}{|c|c|}
\hline $\begin{array}{l}\text { Rivera -Nivar, } \\
\text { Pomales-Garcia } \\
\text { (2010) }\end{array}$ & $\begin{array}{l}\text { Older trainees benefit more from narrative lesson type, no video } \\
\text { background, large display and large font size. }\end{array}$ \\
\hline $\begin{array}{l}\text { Pachman \& Ke } \\
\text { (2012) }\end{array}$ & $\begin{array}{l}\text { Redundancy impairs younger adults' learning but boosts older adults' } \\
\text { learning. }\end{array}$ \\
\hline $\begin{array}{l}\text { Bruder, } \\
\text { Blessing \& } \\
\text { Wandke (2013) }\end{array}$ & $\begin{array}{l}\text { A growing complexity interface is better for older trainees than a } \\
\text { complete interface; adaptive advice does not have much effect on } \\
\text { learning and post-training performance. }\end{array}$ \\
\hline & Goals \\
\hline $\begin{array}{l}\text { Hollis-Sawyer } \\
\& \text { Stern (1999) }\end{array}$ & $\begin{array}{l}\text { Goal-oriented training group scored higher on the post-training, near } \\
\text { transfer, and transfer tasks with regards to mean accuracy and speed. } \\
\text { Goal-oriented group exhibited higher self-efficacy, ,ore positive } \\
\text { attitudes to computers, and were more willing to continue training. }\end{array}$ \\
\hline $\begin{array}{l}\text { Paas, Camp, \& } \\
\text { Rikers (2001) }\end{array}$ & $\begin{array}{l}\text { Goal-specific problems impair learning in both young and old adults, } \\
\text { but the negative effect is larger for older adults. }\end{array}$ \\
\hline $\begin{array}{l}\text { Zumbach \& } \\
\text { Reimann } \\
\text { (2001) }\end{array}$ & GBS boosts task performance, motivation, and self-efficacy. \\
\hline & Error management \\
\hline $\begin{array}{l}\text { Chillarege, } \\
\text { Nordstrom, \& } \\
\text { Williams } \\
(2003)\end{array}$ & $\begin{array}{l}\text { EMT and learning goals are more effective than error avoidance and } \\
\text { performance goals. }\end{array}$ \\
\hline
\end{tabular}


TRAINING FOR OLDER EMPLOYEES: A LITERATURE REVIEW

\begin{tabular}{|c|c|}
\hline $\begin{array}{l}\text { Carter \& Beier } \\
\text { (2010) }\end{array}$ & Low-structure+EMT is more effective for older and younger trainees. \\
\hline \multicolumn{2}{|r|}{ Metacognitive strategies } \\
\hline $\begin{array}{l}\text { Wolfson, } \\
\text { Cavanagh, \& } \\
\text { Kraiger (2014) }\end{array}$ & $\begin{array}{l}\text { Training programs for older employees must have a simple and } \\
\text { consistent design, should be highly structured and based on the } \\
\text { principles of CTML and CLT. }\end{array}$ \\
\hline $\begin{array}{l}\text { Wolfson \& } \\
\text { Kraiger (2014) }\end{array}$ & $\begin{array}{l}\text { Instructional coherence improved information recall and declarative } \\
\text { knowledge. AO's improved the transfer performance of older adults } \\
\text { only. }\end{array}$ \\
\hline \multicolumn{2}{|r|}{ Attitudes } \\
\hline $\begin{array}{l}\text { Kang \& Yoon } \\
(2007)^{\prime}\end{array}$ & $\begin{array}{l}\text { Trial-and-error strategy and cognitive workload are more influenced } \\
\text { by previous experience with technology than by age. }\end{array}$ \\
\hline $\begin{array}{l}\text { Jan, Lu \& Chou } \\
\text { (2012) }\end{array}$ & $\begin{array}{l}\text { Coercive pressure did not affect employees' attitudes to e-learning, but } \\
\text { was effective for adoption of e-learning directly. Normative and } \\
\text { mimetic pressures had a significant influence on employees' attitudes } \\
\text { with mimetic pressure being stronger than normative pressure. No main } \\
\text { effect of age or age interactions was found. }\end{array}$ \\
\hline
\end{tabular}

\section{Discussion}

The present study reviewed the literature on age differences in training. There were several conclusions to this review. Specifically, research shows that older adults learn better when redundancy, error-management, goal-setting, and metacognitive strategies are incorporated into training. Regarding interface design, older trainees benefit from large font size, menu and 
icon-based interfaces, large video size, and empty video background. Ideally, the interface should be simple and may increase in complexity with the course of training. Irrelevant information increases cognitive load on older trainees' attentional resources and should be excluded from instructional materials. Low-structure training seems to work best for older adults when coupled with error-management training.

However, there are many questions that remain unanswered. For example, more research is needed to determine how individual differences interact with training design variables. For example, one of the studies in this review found that error management was especially beneficial for older adults high in cognitive ability (Carter \& Beier, 2010). Another study showed that redundancy benefited older trainees but impaired younger trainees' learning (Wallen \& Mulloy, 2006). Some differences in work motivation were found for white-collar and blue-collar workers as well (Kooij et.al, 2011). It is important to study these and many other individual differences such as fluid and crystallized intelligence, physical and cognitive activity, job type and organizational rank, previous experience with technology, self-efficacy, and susceptibility to stereotype threat to determine how training can be made more effective through individualization.

Another issue that needs to be addressed in future studies is the need to use samples of older adults that are more representative of the current workforce. The emphasis should be on adults 40-67 y.o. with differentiation among young-old, middle-old, and old-old as has been done in some medical studies (Forman et. al., 1992). This will allow for more accurate conclusions about abilities and motives of working-age older adults.

It is also important to examine the impact of different training strategies on younger and older trainees to see whether they are beneficial for both groups, beneficial to only younger or 
older adults, detrimental to both or either of the groups, or ineffective for both or either. Likewise, it is necessary to track the effect of different training strategies on specific training outcomes: As many studies report, a particular intervention is better at improving factual knowledge while another intervention is better at improving conceptual knowledge; or, for example, a novel training method improves near transfer but has no effect on far or problemsolving transfer and so on. Combining different training methods while keeping in mind their differential effects on training outcomes may be a potential avenue for future research.

Finally, socio-ecological models have long been used to understand human behavior and development through the interaction of the individual with his/her environment (Bronfernbrenner, 1994). These models are increasingly used to explain a variety of psychological processes from trauma and healing (Eldebour, Bensel \& Bastein, 1993) to health behaviors (Fleury \& Lee, 2006) to spiritual development in children and adolescents (Lerner, 2008). Socio-ecological models can also be successfully employed to understand organizational behavior, attitudes, and training success. Exploring the multidirectional influences among the individuals, their organizational context, family environments, and sociocultural norms may provide valuable insights into the ways to increase training effectiveness for different age groups and their satisfaction with it.

\section{Potential Limitations}

As with any study, the present study is not without its limitations, and most of these limitations are due to the currently underdeveloped nature of the literature on age and workplace training. First, research on technology-based training for older adults is still scarce and whatever evidence is available sometimes contains conflicting claims, perhaps due to methodological issues. Second, as Van Rooij (2012) points out, it is challenging to generalize the findings of 
empirical studies in the literature review, as most of them are quasi-experiments conducted in the laboratory. She underscores the importance of analyzing training strategies and evaluating training effectiveness in the real-world settings. It is also important, in her opinion, to include organizational context as a moderating variable in the assessment of the training effectiveness. Next, due to the lack of agreement on what constitutes an 'older employee', the variability in the age of trainees among different studies is very high. Moreover, the claim that a given trainee belongs to the cohort of older employees is largely substantiated only by his/her biological age. The problem with this approach is that people age differently, and the variability in their crystallized and fluid intelligence is still significant even in the same age group. Education, socioeconomic status, access to resources, physical activity and mental activity contribute greatly to the levels cognitive health later in life. Therefore, it may be worthwhile to look at individual cognitive functioning to determine the extent of cognitive decline (if any) rather than presume that all older adults need age-specific training.

Finally, it is important to remember that cognitive performance that is observed and measured in the experiments is not a pure expression of cognitive ability. What we are actually looking at is a social construct which includes the actual cognitive ability of an individual, that individual's impression of his/her ability (self-efficacy), others' apprehension of that individual's ability (stereotyping and discrimination), and an individual's idea about others' apprehension of his/her ability (internalization of stigma, anxiety and stigma). As cognitive performance is comprised of so many factors, all of them need to be addressed in training to achieve the best results. Training design must take into account individual's actual crystallized and fluid intelligence, self-efficacy and susceptibility to stereotype threat as well organizational context, legal system and social norms of a particular place and time. In this way, training may improve 
individual learning by targeting internalized negative stereotypes, e-learning attitudes, discrimination, and organizational functioning as a whole.

\section{Conclusion}

Organizational training for older employees remains a little explored subject. However, the aging of the industrialized workforce worldwide necessitates the design of age-appropriate training for adults 40 years of age and above. Some of the training techniques that were shown to improve older adults are instructional coherence, redundancy, goal-setting, and the use of metacognitive strategies. Guidelines for interface design stress the inclusion of menus and icons, large font size, large display size, and empty video background. It is important to examine how these and other elements of training design interact with individual differences to produce the most effective (ideally, customized) training programs. Future research in this area may include exploration of socio-ecological models as they apply to organizational training, experimentation with different design elements, and focus on age cohorts that are more representative of the current workforce. By identifying key findings and gaps in the current literature, the present review is a next step in advancing this research on workplace training for older workers. 


\section{References}

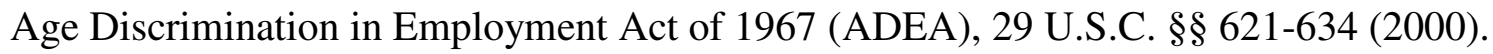

Retrieved from http://www.eeoc.gov/laws/statutes/adea.cfm

Baltes PB, Baltes MM. 1990. Successful aging: Perspectives from the behavioral sciences. New York: Cambridge University Press.

Birren, J. E. (1974). Translations in gerontology: From lab to life: Psychophysiology and speed of response. American Psychologist, 29(11), 808-815.

Bronfenbrenner, U. (1994). Ecological models of human development. Readings on the development of children, $2^{\text {nd }}$ Ed, (pp. 37-43). NY: Freeman.

Buckner, R. L., Head, D., \& Lustig, C. (2006). Brain changes in aging: A lifespan perspective. Lifespan cognition: Mechanisms of change, (pp. 27-42). Oxford: Oxford University Press.

Carstensen LL, Isaacowitz DM, Charles ST. 1999. Taking time seriously: A theory of socioemotional selectivity. Amer. Psyc. 54: 165-81.

Carter, M., \& Beier, M. E. (2010). The effectiveness of error management training with workingage adults. Personnel Psychology, 63, 641-675.

Charness, N. (2009). Skill acquisition in older adults: Psychological mechanisms. Aging and work: Issues and implications in a changing landscape, 232-258.

Charness, N., Kelley, C. L., Bosman, E. A., \& Mottram, M. (2001). Word-processing training and retraining: effects of adult age, experience, and interface. Psychology and aging, 16, 110-127. 
Colcombe, S., \& Kramer, A. F. (2003). Fitness effects on the cognitive function of older adults a meta-analytic study. Psychological science, 14(2), 125-130.

Czaja, S. J., \& Sharit, J. (2009). Aging and work: Issues and implications in a changing landscape. Johns Hopkins Univ Pr.

Elbedour, S., Ten Bensel, R., \& Bastien, D. T. (1993). Ecological integrated model of children of war: Individual and social psychology. Child abuse \& neglect, 17(6), 805-819.

Fleury, J., \& Lee, S. M. (2006). The social ecological model and physical activity in African American women. American journal of community psychology,37(1-2), 129-140.

Forman, D. E., Berman, A. D., McCabe, C. H., Baim, D. S., \& Wei, J. Y. (1992). PTCA in the elderly: the" young-old" versus the" old-old". Journal of the American Geriatrics Society, 40(1), 19-22.

Frey, C. B., \& Osborne, M. A. (2013). The future of employment: how susceptible are jobs to computerisation?. Retrieved from http://www.oxfordmartin.ox.ac.uk/downloads/academic/The_Future_of_Employment.pdf

Ginns, P. (2006). "Integrating information: A meta-analysis of the spatial contiguity and temporal contiguity effects". Learning and Instruction 16: 511-525

Hollis-Sawyer, A., \& Harvey L. Sterns, L. (1999). A novel goal-oriented approach for training older adult computer novices: Beyond the effects of individual-difference factors. Educational Gerontology, 25, 661-684.

Howard, D. V., \& Wiggs, C. L. (1993). Aging and learning: Insights from implicit and explicit tests. In J. Cerella, J. M. Rybash, W. Hoyer, \& M. L. Commons (Eds.). Adult information processing: Limits on loss (pp. 511-527). San Diego, CA: Academic Press. 
Houtkamp, J. M., Toet, A., \& Bos, F. A. (2012). Task-relevant sound and user experience in computer-mediated firefighter training. Simulation \& Gaming,43, 778-802.

Hultsch, D. F. (1977). Changing perspectives on basic research in adult learning and memory. Educational Gerontology, 2, 367-382.

Jan, P. T., Lu, H. P., \& Chou, T. C. (2012). The Adoption of e-Learning: An Institutional Theory Perspective. Turkish Online Journal of Educational Technology-TOJET, 11, 326-343.

Kanfer, R., \& Ackerman, P. L. (2004). Aging, adult development, and work motivation. Academy of management review, 29, 440-458.

Kang, N. E., \& Yoon, W. C. (2008). Age-and experience-related user behavior differences in the use of complicated electronic devices. International journal of human-computer studies, 66, 425-437.

Kelley, C. L., \& Charness, N. (1995). Issues in training older adults to use computers. Behaviour \& Information Technology, 14, 107-120.

Kim, S., Hasher, L., \& Zacks, R. T. (2007). Aging and a benefit of distractibility.Psychonomic Bulletin \& Review, 14(2), 301-305.

Kooij, D. T., De Lange, A. H., Jansen, P. G., Kanfer, R., \& Dikkers, J. S. (2011). Age and work $\square$ related motives: Results of a meta $\square$ analysis. Journal of Organizational Behavior, 32, 197-225.

Lerner, R. M., Roeser, R. W., \& Phelps, E. (Eds.). (2008). Positive youth development \& spirituality: From theory to research. West Conshohocken, PA: Templeton Foundation Press.

Mayer, R. E. (2005). Cognitive theory of multimedia learning. The Cambridge handbook of multimedia learning, 31-48. 
Morris, J. M. (1994). Computer training needs of older adults. Educational Gerontology: An International Quarterly, 20, 541-555.

Ng, T. W., \& Feldman, D. C. (2012). Evaluating Six Common Stereotypes About Older Workers with Meta $\square$ Analytical Data. Personnel Psychology, 65, 821-858.

Paas, F., Camp, G., \& Rikers, R. (2001). Instructional compensation for age-related cognitive declines: Effects of goal specificity in maze learning. Journal of Educational Psychology, 93, 181-186.

Pachman, M., \& Ke, F. (2012). Environmental support hypothesis in designing multimedia training for older adults: Is less always more?. Computers \& Education, 58, 100-110.

Poffenberger, A. T. (1942). Principles of applied psychology. New York: Appleton-Century

Rivera-Nivar, M., \& Pomales-García, C. (2010). E-training: Can young and older users be accommodated with the same interface?. Computers \& Education,55, 949-960.

Salthouse, T. A. (1996). The processing-speed theory of adult age differences in cognition. Psychological review, 103(3), 403-428.

Salthouse, T. A. (2003). Interrelations of aging, knowledge, and cognitive performance. In Understanding Human Development (pp. 265-287). Springer US.

Seeman, Teresa E. (2001). "Social relationships, social support, and patterns of cognitive aging in healthy, high-functioning older adults: MacArthur Studies of Successful Aging.".Health psychology (0278-6133), 20, p. 243-255.

Sweller, J. (1988). Cognitive load during problem solving: Effects on learning.Cognitive science, 12(2), 257-285.

Touron, D. R., \& Hertzog, C. (2004). Distinguishing age differences in knowledge, strategy use, and confidence during strategic skill acquisition.Psychology and aging, 19(3), 452-466. 
U.S. Department of Labor, Bureau of Labor Statistics. (2014, February 26). Civilian labor force by age, sex, race, and ethnicity. Retrieved from http://www.bls.gov/cps/cpsaat03.htm.

U.S. Department of Labor, Bureau of Labor Statistics. (2013, December 19). 2012-2022

Employment projections: Labor force by Bureau of Labor Statistic. Retrieved from http://www.bls.gov/news.release/pdf/ecopro.pdf

Hooren, S. A., Valentijn, A. M., Bosma, H., Ponds, R. W., Boxtel, M. P., \& Jolles, J. (2007). Cognitive Functioning in Healthy Older Adults Aged 64-81: A Cohort Study into the Effects of Age, Sex, and Education. Aging, Neuropsychology, and Cognition, 14, 40-54.

Van Merrienboer, J. J., \& Sweller, J. (2005). Cognitive load theory and complex learning: Recent developments and future directions. Educational psychology review, 17, 147-177.

Van Rooij, S. (2012). Training older workers: Lessons learned, unlearned, and relearned from the field of instructional design. Human Resource Management, 51, 281-298.

Wallen, E. S., \& Mulloy, K. B. (2006). Computer-based training for safety: comparing methods with older and younger workers. Journal of safety research,37, 461-467.

Wolfson, N. E., Cavanagh, T. M., \& Kraiger, K. (2014). Older Adults and Technology-Based Instruction: Optimizing Learning Outcomes and Transfer. Academy of Management Learning \& Education, 13, 26-44.

Wolfson, N. E., \& Kraiger, K. (2014). Cognitive Aging and Training: The Role of Instructional Coherence and Advance Organizers. Experimental aging research,40, 164-186.

Zumbach, J., \& Reimann, P. (2002). Enhancing learning from hypertext by inducing a goal orientation: Comparing different approaches. Instructional Science, 30, 243-267. 